\title{
Everolimus exhibits efficacy as a radiosensitizer in a model of non-small cell lung cancer
}

\author{
HELENA J. MAUCERI ${ }^{1}$, HAROLD G. SUTTON ${ }^{1}$, THOMAS E. DARGA ${ }^{1}$, MASHA KOCHERGINSKY ${ }^{2}$, \\ JOEL KOCHANSKI ${ }^{3}$, RALPH R. WEICHSELBAUM ${ }^{1,5}$ and EVERETT E. VOKES ${ }^{4,5}$ \\ Departments of ${ }^{1}$ Radiation and Cellular Oncology, and ${ }^{2}$ Health Studies, The University of Chicago, \\ Chicago, IL 60637; ${ }^{3}$ Maury Regional Medical Center, Columbia, TN 38401; ${ }^{4}$ Department of \\ Medicine, and ${ }^{5}$ Cancer Center, The University of Chicago, Chicago, IL 60637, USA
}

Received December 5, 2011; Accepted December 27, 2011

DOI: $10.3892 /$ or.2012.1666

\begin{abstract}
Signaling pathways that activate mTOR (mammalian target of rapamycin) are altered in many human cancers and these alterations are associated with prognosis and treatment response. mTOR inhibition can restore sensitivity to DNA damaging agents such as cisplatin. The rapamycin derivative everolimus exhibits antitumor activity and is approved for patients with renal cell cancer. Clinically, everolimus has also been evaluated in patients with advanced non-small cell lung cancer (NSCLC) that were refractory to chemotherapy and epidermal growth factor receptor tyrosine kinase inhibitors. We tested the effects of combined treatment with everolimus (RAD001) and fractionated radiation using a xenograft model of human NSCLC (A549 cells). In growth studies, mean tumor volume was reduced in the everolimus plus $30 \mathrm{~Gy}$ cohort with significant tumor growth suppression compared to $30 \mathrm{~Gy}$ alone $(\mathrm{P}=0015)$, or everolimus alone $(\mathrm{P}<0.001$, ANOVA). Everolimus (20 nM) significantly reduced protein levels of the mTOR downstream effector p70-S6K compared with radiation and vehicle ( $\mathrm{P}=0.05$, ANOVA) and significantly suppressed phospho-p70-S6K levels compared with all other treatments $(\mathrm{P}<0.001$, ANOVA). We also evaluated everolimus and radiation effects on gene expression in A 549 cells. Everolimus $\pm 5 \mathrm{~Gy}$ suppressed endothelin 1 and lactate dehydrogenase expression and increased VEGFA, p21, hypoxia-inducible factor- $1 \alpha$ and SLC2A1 (facilitated glucose transporter 1). mTOR mRNA levels were unaffected while TNF- $\alpha$ levels were increased with everolimus +5 Gy compared to either treatment alone. These findings suggest that everolimus increases the antitumor activity of radiation. Clinical trials combining everolimus with fractionated radiation in patients with NSCLC are warranted.
\end{abstract}

Correspondence to: Dr Helena J. Mauceri, Department of Radiation and Cellular Oncology, The University of Chicago, 900 E. 57th Street, Ludwig Center, Room 6152, Chicago, IL 60637, USA E-mail: hjmaucer@uchicago.edu

Key words: everolimus, radiation sensitization, lung cancer

\section{Introduction}

The mammalian target of rapamycin (mTOR) also known as FK506 binding protein 12-rapamycin associated protein 1 (FRAP1) is a protein which in humans is encoded by the FRAPl gene. Current research indicates that mTOR integrates the input from multiple upstream pathways, including insulin, growth factors (such as IGF-1 and IGF-2), and mitogens. mTOR also functions as a sensor of cellular nutrient and energy levels and redox status (1-3). Mutations in components of the mTOR-related signaling pathways have been described in human malignant diseases (4). Rapamycin is a bacterial product that inhibits mTOR through association with its intracellular receptor FKBP12. The FKBP12-rapamycin complex binds directly to the FKBP12-rapamycin binding (FRB) domain of mTOR. mTOR has been shown to function as the catalytic subunit of two distinct molecular complexes in cells. mTOR, a phosphatidylinositol 3-kinase (PI3K)-related serine/threonine kinase, plays a central role in regulating cell growth, proliferation, and survival, in part by regulation of translation initiation, through interactions with other proteins such as RAPTOR forming the mTOR complex 1 (mTORC1) and RICTOR forming the mTOR complex 2 (mTORC2) $(3,5)$. The best-characterized downstream effectors of mTORC1 are the 70-kDa ribosomal S6 kinase (p70-S6K) and the eukaryotic translation initiation factor 4E-binding protein 1 (4E-BP1). In response to mitogenic stimuli or nutrient availability, mTORC1 is activated leading to phosphorylation of p70S6K and 4E-BP1.

PI3K/Akt signaling represents a major cell survival pathway and recently has been identified as a critical target in anticancer treatment. Activation of PI3K/AKT is associated with malignant transformation and apoptotic resistance. mTOR functions downstream of the PI3K/Akt pathway and is phosphorylated (or activated) in response to stimuli that activate the PI3K/Akt pathway. A report on the mTORC2 Akt Ser ${ }^{473}$ kinase demonstrates that mTOR in the form of mTORC2 acts upstream of Akt. Although mTORC2 is thought to be insensitive to rapamycin, it has been shown that prolonged rapamycin exposure inhibits mTORC 2 assembly and Akt mTOR inhibitors activate Akt while suppressing mTORC1 signaling in different types of cancer cell lines and clinical human tumor samples (6). Currently, it is unclear how mTOR inhibitors activate Akt 
survival signaling. mTOR signaling has emerged as an attractive therapeutic target for cancer therapy and its efficacy in renal cell cancer has been clinically validated $(1,2)$. The potential applications of mTOR inhibitors for treating various types of cancer, including NSCLC, have been actively studied both pre-clinically and clinically (5,7-10). Given their mechanism of action mTOR inhibitors may also enhance the activity of traditional cytotoxic drugs and/or radiation (11-14). A recent study has implicated mTOR inhibition as a target for improving radiotherapy through increasing autophagy, apoptosis and most recently through anti-angiogenic effects (15-19).

We evaluated the effects of combined treatment with everolimus (RAD001, Novartis) and fractionated ionizing radiation using the xenograft model of the human NSCLC model, the A549 cells. We compared tumor growth delay following treatment with everolimus alone, radiation alone and the combination of everolimus and radiation and report that treatment with everolimus plus 30 Gy significantly slowed tumor regrowth compared to 30 Gy alone. Quantitative PCR of A549 cell lysates showed that everolimus suppressed expression of endothelin-1 and lactate dehydrogenase (LDHA) while increasing VEGFA, p21 and SLCA1 (facilitated glucose transporter 1) expression. Taken together our data suggests that everolimus may be combined with radiation to treat NSCLC and should be investigated in an effort to improve treatment outcomes.

\section{Materials and methods}

Cell culture. A549 human non-small cell lung carcinoma cells were obtained from the American Type Culture Collection (Manassas, VA) and were cultured using RPMI-1640 culture medium (Invitrogen, Carlsbad, CA) supplemented with $10 \%$ fetal bovine serum (Atlanta Biologicals, Lawrenceville, GA), $100 \mathrm{U} / \mathrm{ml}$ penicillin and $100 \mathrm{mg} / \mathrm{ml}$ streptomycin (Invitrogen). Cultures were maintained at $37^{\circ} \mathrm{C}$ in a humidified environment containing $5 \% \mathrm{CO}_{2}$.

Xenograft experiments. Athymic nude female mice were obtained from FCRI-Taconic (Germantown, NY). A549 cells ( $1 \times 10^{7}$ cells in $\left.100 \mu 1 \mathrm{PBS}\right)$ were injected subcutaneously into the right hind limb. When the mean tumor volume reached $232.5 \pm 9.5 \mathrm{~mm}^{3}$, mice were divided into one of the following treatment groups; control, radiation (six 5 Gy fractions for a total dose of $30 \mathrm{~Gy})$, everolimus alone $(10 \mathrm{mg} / \mathrm{kg}$ by oral gavage for 6 days), and everolimus plus 30 Gy (six 5 Gy fractions $+10 \mathrm{mg} / \mathrm{kg}$ everolimus $90 \mathrm{~min}$ prior to irradiation). Control animals and mice in the radiation alone group were gavaged with deionized water. Radiation was administered using a Phillips orthovoltage X-ray generator operating at $250 \mathrm{kV}$ and $15 \mathrm{~mA}$. Mice were restrained in plexiglass cages and all limbs, but the tumor bearing hind limb, were shielded with lead. Tumor volume was determined by direct measurement with calipers and calculated using the formula for the volume of an ellipsoid as previously described (20). At the conclusion of each experiment the animals were euthanized using $\mathrm{CO}_{2}$ followed by cervical dislocation in accordance with institutional guidelines.

In vitro studies. A549 cells $\left(5 \times 10^{6}\right)$ were plated in each well of 6-well plates. Forty-eight hours later the cells were pre- treated with $20 \mathrm{nM}$ everolimus in DMSO, or an equal volume of DMSO (placebo), and exposed to 5 Gy. Twenty-four hours later cells were lysed with either $1 \mathrm{ml}$ TRIzol (Invitrogen) for RNA extraction or $500 \mu \mathrm{l}$ Cell Extraction Buffer (Invitrogen, cat.\# FNN0011) with protease inhibitor cocktail (Sigma cat.\# P-2714) and $1 \mathrm{mM}$ PMSF for ELISAs.

ELISA. Levels of phospho-threonine 389 (T-389) p70-S6K (Invitrogen, cat\# KHO0581) and of total p70-S6K (Invitrogen cat.\# KHO0571) were determined by ELISA following the manufacturer's protocols. Values obtained were normalized to the total protein concentration determined by the BCA Protein Assay kit (Pierce). Data are expressed as $\mu \mathrm{g} / \mathrm{mg}$ protein $\pm \mathrm{SD}$.

RNA extraction and cDNA synthesis. Total RNA $(2 \mu \mathrm{g})$ was subjected to DNAse treatment using DNAse I (Invitrogen). DNAse-treated RNA (10 $\mu \mathrm{l})$ was converted to cDNA using the High Capacity cDNA Reverse Transcription kit (Applied Biosystems).

Quantitative PCR. Quantitative PCR was performed in triplicate using default conditions on an ABI 7900HT in 384-well plates in a $5 \mu 1$ reaction volume consisting of $2.5 \mu 1$ Power SYBR-Green PCR Master mix (Applied Biosystems), $0.5 \mu 1$ $10 \mu \mathrm{M}$ primer mixture and $2 \mu \mathrm{l}$ of 1:200 diluted cDNA. GAPDH was used as the endogeneous control and fold change calculations were performed using the comparative $\mathrm{Ct}$ method. The sequences of the primers used are shown in Table I.

Statistical analyses. Repeated measures analysis of variance (ANOVA) models were used to determine significant differences in tumor growth between the four treatment groups. The response variable (tumor volume) was log-transformed to satisfy the normality assumption. The fixed effects included the log-transformed baseline tumor volume measurement, treatment group, day, day $^{2}$, treatment $\mathrm{x}$ day, and treatment $\mathrm{x}$ day $^{2}$ interaction terms. Correlation between multiple tumor volume measurements on each mouse were modeled using the covariance matrix with spatial power correlation structure, which allows for unequal time intervals. Satterthwaite's degrees of freedom approximation was used due to unequal variances in the treatment groups. A generalized F-test was used to test the composite hypothesis of no difference between treatment, treatment $\mathrm{x}$ day and treatment $\mathrm{x} \mathrm{day}{ }^{2}$, essentially comparing tumor growth curves between treatments. The reported p-values for the F-test are unadjusted for multiple comparisons. All analyses were performed using PROC MIXED in the SAS/STAT v.9.2 software.

\section{Results}

Combination treatment with radiation and everolimus significantly inhibits tumor regrowth. We hypothesized that everolimus could be employed as a radiosensitizing agent. Tumor measurements on Day 23 showed that mean volume was reduced in the everolimus plus $30 \mathrm{~Gy}$ treatment group $\left(225.4 \pm 34.2 \mathrm{~mm}^{3}\right)$ compared to $30 \mathrm{~Gy}(5 \mathrm{~Gy} \mathrm{x} 6)$ alone $\left(393.7 \pm 51.2 \mathrm{~mm}^{3}\right)$, everolimus alone $\left(510.4 \pm 93.5 \mathrm{~mm}^{3}\right)$ and control $\left(820 \pm 158.8 \mathrm{~mm}^{3}\right)$. At the end of the treatment the control mean tumor volume had reached $2040.5 \pm 373.3 \mathrm{~mm}^{3}$, that of everolimus alone was 
Table I. PCR primer sequences.

\begin{tabular}{|c|c|c|c|}
\hline Name & Accession numbers & Primers & Sequences $\left(5^{\prime}-3^{\prime}\right)$ \\
\hline GAPDH & NM_002046 & $\begin{array}{l}\text { Forward } \\
\text { Reverse }\end{array}$ & $\begin{array}{l}\text { TGC ACC ACC AAC TGC TTA GC } \\
\text { GGC ATG GAC TGT GGT CAT GAG }\end{array}$ \\
\hline END1 & NM_001955 & $\begin{array}{l}\text { Forward } \\
\text { Reverse }\end{array}$ & $\begin{array}{l}\text { TCT CTG CTG TTT GTG GCT TG } \\
\text { CCA GGG TGG ACT GGG AGT }\end{array}$ \\
\hline HIF1A & NM_001530 & $\begin{array}{l}\text { Forward } \\
\text { Reverse }\end{array}$ & $\begin{array}{l}\text { GAA GTG GCA ACT GAT GAG CA } \\
\text { GCG CGA ACG ACA AGA AA }\end{array}$ \\
\hline IGF2 & NM_000612 & $\begin{array}{l}\text { Forward } \\
\text { Reverse }\end{array}$ & $\begin{array}{l}\text { AGA AGC ACC AGC ATC GAC TT } \\
\text { GTT CGG TTT GCG ACA CG }\end{array}$ \\
\hline LDHA & NM_005566 & $\begin{array}{l}\text { Forward } \\
\text { Reverse }\end{array}$ & $\begin{array}{l}\text { GGA GAT CCA TCA TCT CTC CC } \\
\text { GGC CTG TGC CAT CAG TAT CT }\end{array}$ \\
\hline MTOR & NM_004958 & $\begin{array}{l}\text { Forward } \\
\text { Reverse }\end{array}$ & $\begin{array}{l}\text { TCC GGC TGC TGT AGC TTA TT } \\
\text { CCA ACA GTT CAC CCT CAG GT }\end{array}$ \\
\hline CDKN1A (p21) & NM_000389 & $\begin{array}{l}\text { Forward } \\
\text { Reverse }\end{array}$ & $\begin{array}{l}\text { GGACAGCAGAGGAAGACC } \\
\text { TGGTAGAAATCTGTCATGCTG }\end{array}$ \\
\hline SLC2A1 & NM_006516 & $\begin{array}{l}\text { Forward } \\
\text { Reverse }\end{array}$ & $\begin{array}{l}\text { GGC ATT GAT GAC TCC AGT GTT } \\
\text { ATG GAG CCC AGC AGC AA }\end{array}$ \\
\hline $\mathrm{TNF}$ & NM_000594 & $\begin{array}{l}\text { Forward } \\
\text { Reverse }\end{array}$ & $\begin{array}{l}\text { GCC AGA GGG CTG ATT AGA GA } \\
\text { TCA GCC TCT TCT CСT TCC TG }\end{array}$ \\
\hline VEGFA & NM_003376 & $\begin{array}{l}\text { Forward } \\
\text { Reverse }\end{array}$ & $\begin{array}{l}\text { CTA CCT CCA CCA TGC CAA GT } \\
\text { ATG TTG GAC TCC TCA GTG GG }\end{array}$ \\
\hline
\end{tabular}

$1464.2 \pm 330.8 \mathrm{~mm}^{3}$, of 30 Gy was $945.3 \pm 211.1 \mathrm{~mm}^{3}$, while that of everolimus +30 Gy treatment was $507.7 \pm 77.1 \mathrm{~mm}^{3}$. Importantly, combined treatment with everolimus $+30 \mathrm{~Gy}$ significantly slowed tumor regrowth compared to 30 Gy alone ( $\mathrm{P}=0015$, ANOVA, Fig. 1) suggesting that everolimus can effectively be combined with fractionated radiotherapy.

Everolimus significantly decreases p70-S6K levels and phosphorylation of S6K1 T-389. mTOR inhibition by everolimus was evaluated by examining the protein levels of the mTOR downstream target ribosomal p70-S6K. A549 cells were treated with $20 \mathrm{nM}$ everolimus or placebo (DMSO) with or without 5 Gy and lysates were prepared for analysis. Treatment with everolimus alone significantly reduced $\mathrm{p} 70-\mathrm{S} 6 \mathrm{~K}$ protein levels $(42.8 \pm 7.6 \mu \mathrm{g} / \mathrm{ml})$ compared with placebo $(70.1 \pm 12.6 \mu \mathrm{g} / \mathrm{ml})$, placebo plus radiation $(55.0 \pm 2.4 \mu \mathrm{g} / \mathrm{ml})$ and everolimus plus radiation $(51.2 \pm 12.9 \mu \mathrm{g} / \mathrm{ml}, \mathrm{P}=0.05$, ANOVA, Fig. $2 \mathrm{~A})$. We next evaluated the effects of everolimus on the phosphorylation of S6K1 T-389. Everolimus significantly suppressed phospho-p70-S6K levels by $80 \%(5.9 \pm 0.7)$ compared with placebo $(30.0 \pm 2.6)$ and by $77 \%$ compared with placebo plus radiation (25.5 $\pm 4.1, \mathrm{P}<0.001$, ANOVA). No further reduction in phosphorylation was observed when everolimus was combined with radiation $(6.6 \pm 1.0$, Fig. $2 \mathrm{~B})$. These findings confirm that everolimus significantly inhibits mTOR activity in A549 cells.

Everolimus alters gene expression in A549 cells. Because mTOR is a sensor of nutrient and growth factor signaling, we evaluated the effects of mTOR inhibition by everolimus alone and in combination with radiation on gene expression in A549 tumor cells. We evaluated expression of five hypoxia-inducible

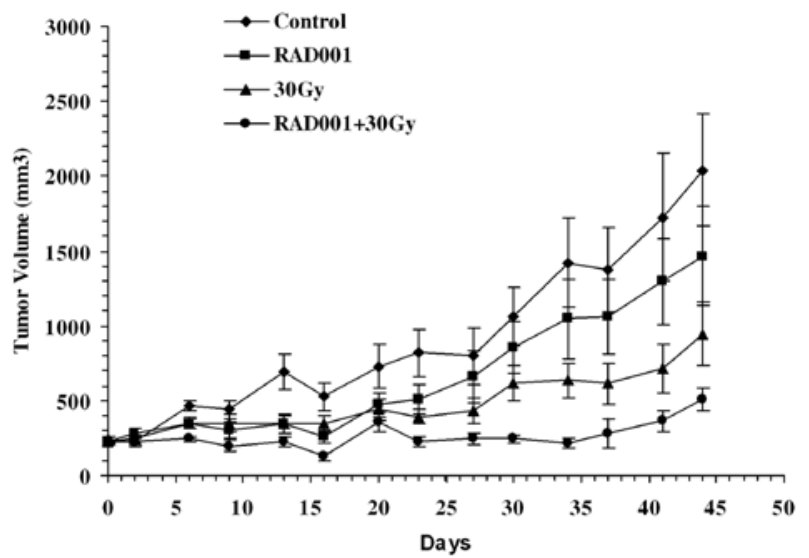

Figure 1. Growth of A549 tumors following treatment with RAD001 (everolimus) and radiation. A549 cells were injected into the hind limb of female nude mice. Mice were treated six times with $10 \mathrm{mg} / \mathrm{kg}$ RAD001 by oral gavage 90 min prior to 30 Gy (5 Gy x 6 fractions). Treatment with RAD001 + $30 \mathrm{~Gy}$ significantly slowed tumor growth compared to $30 \mathrm{~Gy}$ alone $(\mathrm{P}=0015)$.

factor-1 $\alpha$ (HIF-1 $\alpha)$ target genes and two glycolysis genes. Endothelin-1 gene expression was suppressed $50 \%$ by everolimus alone and in combination with 5 Gy. HIF-1 $\alpha$ expression was not affected by everolimus alone, but was induced 2 -fold by radiation and 3 -fold by the everolimus plus $5 \mathrm{~Gy}$. Expression of insulin-like growth factor 2 (IGF-2) was increased 1.7-fold by everolimus, decreased slightly by 5 Gy and unchanged by everolimus plus 5 Gy. VEGFA was induced 2-fold by everolimus, not affected by radiation, and induced 3.9 -fold by everolimus plus 5 Gy.p21 (Cip 1, CDKN1A) expression was induced 2.7-fold by everolimus treatment, 3.2-fold by radiation and the combination 

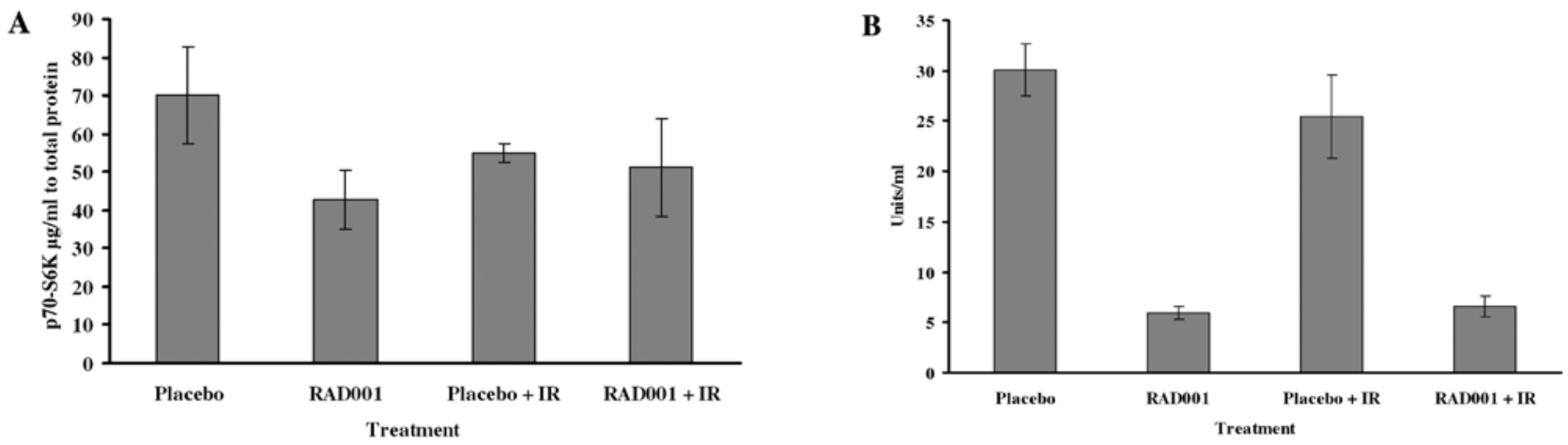

Figure 2. Effects of everolimus and radiation on p70-S6K protein levels and S6K1 T-389 phosphorylation in A549 human non-small cell lung carcinoma cells. (A) Total p70-S6K in A549 cells treated with everolimus and radiation. A549 cells were treated with $20 \mathrm{nM}$ everolimus or placebo (DMSO) \pm 5 Gy and cell lysates prepared. RAD001 alone significantly reduced p70-S6K protein levels $(42.8 \pm 7.6 \mu \mathrm{g} / \mathrm{ml})$ compared to placebo $(70.1 \pm 12.6 \mu \mathrm{g} / \mathrm{ml})$, placebo $+5 \mathrm{~Gy}$ $(55.0 \pm 2.4 \mu \mathrm{g} / \mathrm{ml})$ and RAD001 $+5 \mathrm{~Gy}(51.2 \pm 12.9 \mu \mathrm{g} / \mathrm{ml}, \mathrm{P}=0.05$, ANOVA). (B) S6K1 T-389 phosphorylation in A549 cells treated with $20 \mu \mathrm{M}$ everolimus.

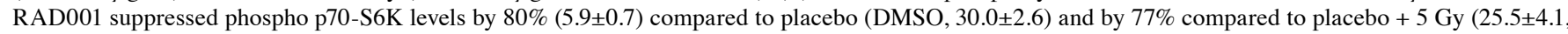
$\mathrm{P}<0.001$, ANOVA). No further reduction in phosphorylation was observed with RAD001 + 5 Gy $(6.6 \pm 1.0)$.

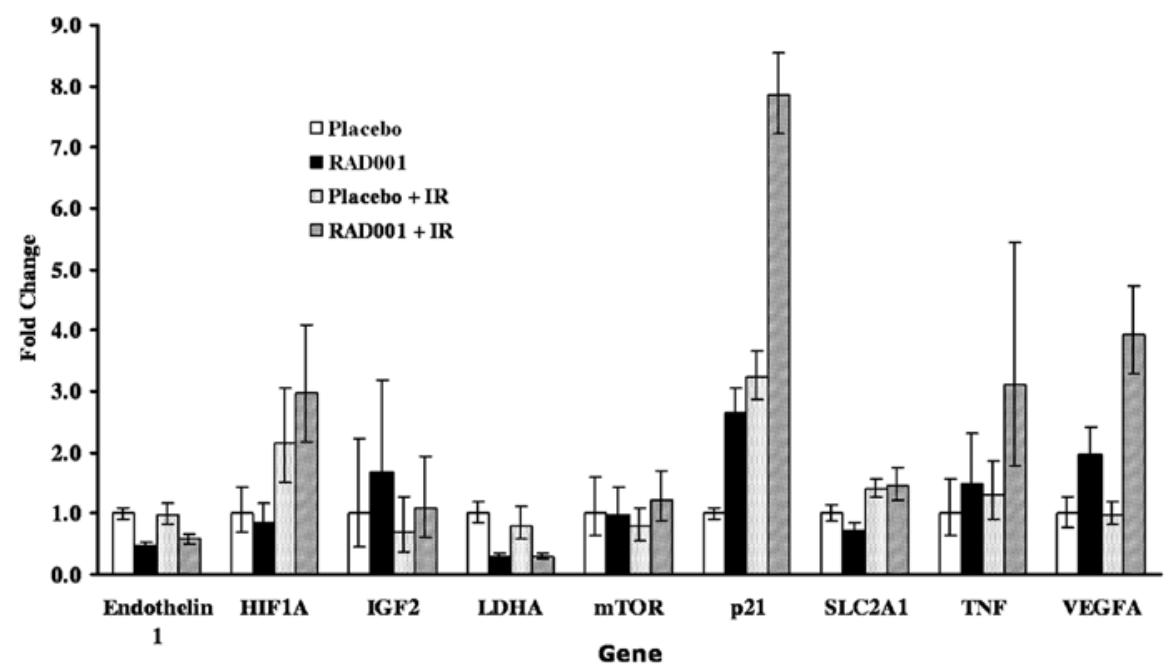

Figure 3. Gene expression in A549 cells following treatment with everolimus and radiation. Endothelin 1 was suppressed 50\% by RAD001 alone and in combination with $5 \mathrm{~Gy}$ (compared to placebo). HIF-1 $\alpha$ was not affected by RAD001 alone, but was induced 2 -fold by 5 Gy and 3 -fold by RAD001 + 5 Gy. IGF2 was increased 1.7-fold by RAD001, decreased slightly by $5 \mathrm{~Gy}$ and unchanged by RAD001 $+5 \mathrm{~Gy}$. LDHA was not affected by 5 Gy but was suppressed $70 \%$ by RAD001 alone and in combination with $5 \mathrm{~Gy}$. mTOR mRNA levels were not affected by any treatment. p21 was induced 2.7-fold by RAD001,3.2-fold by 5 Gy and 7.9-fold by RAD001 + 5 Gy. SLC2A1 was only slightly suppressed by RAD001 alone, and induced $50 \%$ by 5 Gy. TNF- $\alpha$ expression was slightly increased by RAD001 (1.5-fold) and 5 Gy (1.3-fold). RAD001 + 5 Gy produced a 3-fold induction in TNF- $\alpha$ expression. VEGFA was induced 2-fold by RAD001, not affected by $5 \mathrm{~Gy}$, and induced 3.9 -fold by RAD001 +5 Gy. Quantitative PCR was performed in triplicate.

of everolimus and radiation increased CDKN1A expression by 7.9-fold. LDHA expression was not affected by radiation but was suppressed $70 \%$ by everolimus alone and in combination with radiation. SLC2A1 was only slightly suppressed by everolimus alone, and was induced $50 \%$ by radiation. This radiation induction was not affected by everolimus. mTOR mRNA levels were not affected by radiation, everolimus or everolimus plus radiation. TNF- $\alpha$ expression was slightly increased by everolimus (1.5-fold) and radiation (1.3-fold). A 3-fold induction in TNF- $\alpha$ expression was observed following treatment with everolimus plus 5 Gy (Fig. 3).

\section{Discussion}

The use of mTOR inhibitors as single agents has been shown to improve treatment outcomes in several types of cancer. The combination of mTOR inhibitors and other treatment modali- ties is under active clinical investigation and the combination of mTOR inhibitors with other anti-cancer agents has been reported in the literature (1-3,5). As a single agent, everolimus can be administered orally and is generally well-tolerated with toxicities consisting of mouth mucositis and myelosuppression as well as hyperglycemia and dyslipidemia. Everolimus has been approved by the FDA for the treatment of renal cell cancer and is currently being employed in clinical trials of several hematologic and solid tumors including NSCLC $(21,22)$. To date, its single agent activity in NSCLC has been disappointing (23). Everolimus has also been combined with other agents. For example, the effects of combined treatment with everolimus (5 mg/day) and gefitinib have been evaluated in a phase I trial of patients with advanced NSCLC $(24,25)$.

We examined the interaction between everolimus and radiation in a preclinical lung cancer model because radiotherapy at a total dose of $70 \mathrm{~Gy}$ is commonly used to treat NSCLC. A549 
human lung carcinoma xenografts were established in nude mice. This cell line was chosen because A549 cells have a deletion of the p16 gene, and because they are p53 wild-type and radioresistant. Although we did not attempt to maximize the dosing schedule by treating the mice before and after radiation or continued treatment with everolimus after termination of radiation treatment, everolimus significantly enhanced radiation antitumor effects. These findings are in agreement with those of Manegold et al, where improved tumor growth control was observed when everolimus was combined with fractionated radiotherapy for the treatment of colon and pancreatic tumors (19).

As previously reported, treatment with everolimus significantly decreases p70-S6K levels and phosphorylation of S6K1 T-389 in A549 cells. We verified the effects of everolimus and radiation on gene expression in A549 cells and report that p21 expression was elevated $24 \mathrm{~h}$ after treatment with everolimus $(20 \mathrm{nM})$, radiation (5 Gy) and everolimus plus $5 \mathrm{~Gy}$. Beuvink et al reported that everolimus enhanced the effect of cisplatin in A549 cells by inhibiting expression of p21 and by reducing p21 protein levels (13). In our studies we noted that p21 mRNA levels were not affected by everolimus. We also showed that endothelin-1 was inhibited $50 \%$ by everolimus alone and with 5 Gy. Unlike the data reported on prostate cancer by Majumder et al, we did not detect downregulation of HIF-1 $\alpha$ target genes or HIF-1 $\alpha$ activity following treatment with everolimus (26).

Our results suggest that everolimus can increase the antitumor activity of radiation and support a clinical trial with combination of everolimus and radiation in patients with NSCLC. While single agent activity for everolimus in NSCLC has not been demonstrated our data suggest that its use with radiation should be explored. A phase clinical I trial combining everolimus with radiation has been initiated at our institution. The enhancement of radiotherapy by everolimus suggests clinical potential. Treatment with radiation and various inhibitors, for example apoptosis inhibitors, may enhance the therapeutic ratio of radiation and perhaps prolong survival.

\section{Acknowledgements}

Dr R.R. Weichselbaum is a consultant to Catherex, Inc., Reflexion Medical, Inc. and Midway Pharmaceuticals, Inc. Dr E.E. Vokes is a consultant and received funding from Novartis.

\section{References}

1. Meric-Bernstam F and Gonzalez-Angulo AM: Targeting the mTOR signaling network for cancer therapy. J Clin Oncol 27: 2278-2287, 2009 .

2. Klumpen HJ, Beijnen JH, Gurney H and Schellens JH: Inhibitors of mTOR. Oncologist 15: 1262-1269, 2010.

3. Vilar E, Perez-Garcia J and Tabernero J: Pushing the envelope in the mTOR pathway: the second generation of inhibitors. Mol Cancer Ther 10: 395-403, 2011

4. Huang S, Bjornsti MA and Houghton PJ: Rapamycins: mechanism of action and cellular resistance. Cancer Biol Ther 2: 222-232, 2003.

5. Fasolo A and Sessa C: Current and future directions in mammalian target of rapamycin inhibitors development. Expert Opin Investig Drugs 20: 381-394, 2011.

6. Wang X, Yue P, Kim YA, et al: Enhancing mammalian target of rapamycin (mTOR)-targeted cancer therapy by preventing $\mathrm{mTOR} /$ raptor inhibition-initiated, mTOR/rictor-independent Akt activation. Cancer Res 68: 7409-7418, 2008.
7. Pal SK, Figlin RA and Reckamp K: Targeted therapies for non-small cell lung cancer: an evolving landscape. Mol Cancer Ther 9: 1931-1944, 2010.

8. Gridelli C, Maione P and Rossi A: The potential role of mTOR inhibitors in non-small cell lung cancer. Oncologist 13: 139-147, 2008.

9. Dhillon T, Mauri FA, Bellezza G, et al: Overexpression of the mammalian target of rapamycin: a novel biomarker for poor survival in resected early stage non-small cell lung cancer. J Thorac Oncol 5: 314-319, 2010.

10. Memmott RM and Dennis PA: The role of the Akt/mTOR pathway in tobacco carcinogen-induced lung tumorigenesis. Clin Cancer Res 16: 4-10, 2010.

11. Soria JC, Shepherd FA, Douillard JY, et al: Efficacy of everolimus (RAD001) in patients with advanced NSCLC previously treated with chemotherapy alone or with chemotherapy and EGFR inhibitors. Ann Oncol 20: 1674-1681, 2009.

12. $\mathrm{Pu} \mathrm{X}$, Hildebrandt $\mathrm{MA}, \mathrm{Lu} \mathrm{C}$, et al: $\mathrm{PI} 3 \mathrm{~K} / \mathrm{PTEN} / \mathrm{AKT} /$ mTOR pathway genetic variation predicts toxicity and distant progression in lung cancer patients receiving platinum-based chemotherapy. Lung Cancer 71: 82-88, 2011.

13. Beuvink I, Boulay A, Fumagalli S, et al: The mTOR inhibitor RAD001 sensitizes tumor cells to DNA-damaged induced apoptosis through inhibition of p21 translation. Cell 120: 747-759, 2005.

14. Wangpaichitr M, Wu C, You M, et al: Inhibition of mTOR restores cisplatin sensitivity through down-regulation of growth and anti-apoptotic proteins. Eur J Pharmacol 591: 124-127, 2008.

15. Jaboin JJ, Shinohara ET, Moretti L, et al: The role of mTOR inhibition in augmenting radiation induced autophagy. Technol Cancer Res Treat 6: 443-447, 2007.

16. Shinohara ET, Cao C, Niermann K, et al: Enhanced radiation damage of tumor vasculature by mTOR inhibitors. Oncogene 24: 5414-5422, 2005.

17. Nagata Y, Takahashi A, Ohnishi K, et al: Effect of rapamycin, an mTOR inhibitor, on radiation sensitivity of lung cancer cells having different p53 gene status. Int J Oncol 37: 1001-1010, 2010.

18. Kim KW, Moretti L, Mitchell LR, et al: Combined Bcl-2/ mammalian target of rapamycin inhibition leads to enhanced radiosensitization via induction of apoptosis and autophagy in non-small cell lung tumor xenograft model. Clin Cancer Res 15: 6096-6105, 2009.

19. Manegold PC, Paringer C, Kulka U, et al: Antiangiogenic therapy with mammalian target of rapamycin inhibitor RAD001 (Everolimus) increases radiosensitivity in solid cancer. Clin Cancer Res 14: 892-900, 2008.

20. Hallahan DE, Mauceri HJ, Seung LP, et al: Spatial and temporal control of gene therapy using ionizing radiation. Nat Med 1: 786-791, 1995.

21. Janku F, Stewart DJ and Kurzrock R: Targeted therapy in non-small cell lung cancer - is it becoming a reality? Nat Rev Clin Oncol 7: 401-414, 2010.

22. O'Donnell A, Faivre S, Burris HA III, et al: Phase I pharmacokinetic and pharmacodynamic study of the oral mammalian target of rapamycin inhibitor everolimus in patients with advanced solid tumors. J Clin Oncol 26: 1588-1595, 2008.

23. Papadimitrakopoulou V, Soria JC, Douillard JY, Giaccone G, Wolf J, Crino L, Cappuzzo F, Sharma S, Gross SH and Shepherd FA: A phase II study of RAD001 (everolimus) monotherapy in patients with advanced non-small cell lung cancer (NSCLC) failing prior platinum-based chemotherapy or prior C and EGFR inhibitors (EGFR-1). J Clin Oncol 25: 7589, 2007.

24. Milton DT, Kris MG, Azzoli CG, Gomez JE, Heelan R, Krug LM, Pao W, Pizzo B, Rizvi NA and Miller VA: PhaseI/ II trial of gefitinib and RAD001 (Everolimus) in patients with advanced non-small cell lung cancer (NSCLC). J Clin Oncol 23: 7104, 2005.

25. Papadimitrakopoulou V, Blumenschein GR, Leighl NB, Bennouna J, Soria JC, Burris HA III, Dimitrijevic S, Kunz T, Di Scala L and Johnson BE: A phase 1/2 study investigating the combination of RAD001 (everolimus) and erlotinib as 2nd and 3rd line therapy in patients with advanced non-small cell lung cancer (NSCLC) previously treated with chemotherapy: phase 1 results. J Clin Oncol 26: 8051, 2008.

26. Majumder PK, Febbo PG, Bikoff R, et al: mTOR inhibition reverses Akt-dependent prostate intraepithelial neoplasia through regulation of apoptotic and HIF-1-dependent pathways. Nat Med 10: 594-601, 2004. 